\title{
Canine vector-borne infections in Mauritius
}

\author{
Gary Kwok Cheong Lee ${ }^{1}$, Jean Alain Ean Ignace ${ }^{2}$, Ian Duncan Robertson ${ }^{1}$ and Peter John Irwin ${ }^{1 *}$
}

\begin{abstract}
Background: Canine vector-borne diseases have a worldwide distribution, but to the best of our knowledge, no research has been carried out to evaluate their presence on the Indian Ocean island of Mauritius. An investigation into canine vector-borne infections was conducted in dogs $(n=78)$ resident at an animal shelter in Port Louis, Mauritius using a combination of traditional microscopy and serological methods.

Methods: Ticks were manually collected from the stray dog population for identification as well as for quantifying tick burdens. Blood was also collected from each dog via either the jugular vein or the cephalic vein, and was stored in EDTA tubes. The stored blood was then used to measure PCV values, make blood smears for the identification of parasites, and used for serological testing of vector-borne disease.

Results: A total of 178 ticks were collected from 52 dogs and identified as Rhipicephalus sanguineus (175/178) or Amblyomma variegatum (3/178). Twenty-six (33\%; 95\% Cl 23,45) dogs were seropositive for Ehrlichia spp., and 12 (15\%; 95\% Cl 8, 25) for Anaplasma spp., Dirofilaria antigen was detected in 14 (18\%; 95\% Cl 10, 28), and nine (12\%; $95 \% \mathrm{Cl} 5,21)$ dogs had Hepatozoon canis gamonts observed in blood films during microscopic examination. Eleven $(14 \% ; 95 \% \mathrm{Cl} 7,24)$ dogs were co-infected with two pathogens. Borrelia burgdorferi antibodies were not detected in any dogs.
\end{abstract}

Conclusions: Infection with these pathogens had no significant effect on the packed cell volume (PCV), but high tick burdens were significantly associated with the presence of a tick-borne pathogen. This is the first study of its kind on the dog population in Mauritius and demonstrates the presence of previously undocumented canine vector-borne infections on the island. The relatively high proportion of infected dogs within the study should alert clinicians to the presence of canine vector-borne diseases on the island of Mauritius.

Keywords: Mauritius, Ehrlichia, Anaplasma, Dirofilaria immitis, Hepatozoon canis, Rhipicephalus sanguineus, Amblyomma variegatum, Canine vector-borne diseases

\section{Background}

Mauritius is an island of volcanic origin that lies within the South-West Indian Ocean $\left(20^{\circ} 17^{\prime} \mathrm{S}\right.$ and $\left.57^{\circ} 33^{\prime} \mathrm{E}\right)$. The climate is tropical with hot and humid summers and warm and drier winters. Average temperatures at sea level are moderately high $\left(22-31^{\circ} \mathrm{C}\right)$ and decrease with increasing altitude to a minimum of $12^{\circ} \mathrm{C}$ (maximum altitude $904 \mathrm{~m}$ ) [1]. The mean humidity around the island is generally $>80 \%$ but rainfall varies significantly between regions, with approximately $5000 \mathrm{~mm} /$ year on the high grounds and only $1000 \mathrm{~mm} /$ year in the coastal regions. Domestic dogs were introduced to the island by Dutch settlers in the 17th Century, and many

\footnotetext{
* Correspondence: P.Irwin@murdoch.edu.au

${ }^{1}$ Vector and Water-Borne Pathogen Research Group, School of Veterinary and Life Sciences, Murdoch University, Murdoch, WA 6150, Australia

Full list of author information is available at the end of the article
}

dogs nowadays roam the island as strays. The large numbers of stray dogs together with favourable climatic conditions are ideal to facilitate the transmission of vector-borne pathogens.

Canine ehrlichiosis, anaplasmosis, hepatozoonosis and dirofilariasis are vector-borne diseases with a worldwide distribution, yet to the best of our knowledge there have been no studies into the occurrence or prevalence of these diseases in dogs in Mauritius [1,2]. With the exception of dirofilariasis (heartworm disease) that is transmitted by mosquitoes, these diseases are transmitted by ticks, notably Rhipicephalus sanguineus (the brown dog tick), which itself has a ubiquitous geographical distribution and has been reported on Mauritius [1]. From a clinical perspective, vector-borne diseases traditionally pose a diagnostic challenge due to their nonspecific symptomology and often sub-clinical nature, 
thus a high degree of diagnostic suspicion is required by veterinarians in order to make a diagnosis [3].

The objective of this investigation was to conduct a cross-sectional study using a combination of serological and traditional microscopic techniques to determine the presence of haemotropic vector-borne infections in a population of impounded dogs in Mauritius and, in addition, to identify the ticks infecting these dogs.

\section{Methods}

\section{Study population and sample collection}

Sampling was conducted at an animal shelter operated by the Mauritius Society for Animal Welfare (MSAW) in Port Louis, the capital city of Mauritius, in January 2014, with approval of the Murdoch University Animal Ethics Committee (Permit No. R2622/13). This shelter serves as the island's main pound and receives stray dogs from all over the country. There are approximately 10-15 dogs impounded each day, including dogs of all ages (including puppies) and breeds. Dogs that are suffering from overt diseases are euthanized upon arrival. The other dogs are impounded for three days. The dogs that have not been reclaimed after three days are either euthanized or kept for rehoming at the MSAW headquarters in Rose Hill should they be in apparently good health.

Each dog was restrained and examined for ticks, which were collected by gentle manual removal and immediately placed in tubes containing 70\% ethanol for later identification. Each dog was also given a tick burden score (low, medium or high) depending on the total number of visible ticks on the dog at the time of collection. Anatomical regions assessed were the head, ears, neck, thorax, abdomen, fore and hind limbs, interdigital areas, axilla, tail and inguinal area. A low score represented the presence of $<10$ ticks in all locations, a medium burden indicated 10 to 20 ticks, and for a high score $>20$ ticks were observed and recorded. Ticks were later examined under a dissecting stereo microscope (SZ61, Olympus, Japan) and identified to species level using standard keys $[4,5]$.

A blood sample was collected from either the jugular or the cephalic vein, using standard technique. The blood was immediately transferred into $2.5 \mathrm{ml}$ tubes containing ethylene diamine tetra acetic acid (EDTA); the tube was gently inverted to thoroughly mix the anticoagulant, and two blood smears were made on glass microscope slides within two hours of collection. Blood films were fixed in methanol immediately and later stained using a commercial available Romanowski staining system (Diff Quik, Harleco, USA).

\section{Serological testing, laboratory measurements and microscopic examination}

Anticoagulated blood was used on the same day to detect antibodies to Ehrlichia canis, Ehrlichia ewingii,
Anaplasma phagocytophilum, A. platys, and Borrelia burgdorferi, and antigen of Dirofilaria immitis using a cage-side immunochromatographic test (Snap 4Dx Plus, IDEXX laboratories, Westbrook, ME, USA), according to the manufacturer's instructions. The packed cell volume (PCV) was measured using the EDTA-stored blood using a portable centrifuge (ZIPocrit, Shanghai LW Scientific Co. Ltd., Shanghai, China). The blood smears were evaluated using the technique described by Allison et al. [6]; forty medium power (X400) fields were evaluated for each smear.

\section{Statistical analysis}

The data from PCV values and the presence of pathogens (Ehrlichia, Anaplasma, Dirofilaria, and Hepatozoon spp.) were coded and analysed with analysis of variance (ANOVA), after testing for homogeneity of variances with the Levene Statistic. A Pearson's Chi-square test was used to assess the relationship between tick burden, presence of pathogens and gender. Co-infections with different pathogens were treated as an individual entity. All results were considered to be significant at $\mathrm{p} \leq 0.05$.

\section{Results}

Dogs

A total of 78 dogs were examined and sampled for inclusion in this study. These comprised 39 male and 39 females, of a variety of breeds and cross-breeds (data not shown).

\section{Ticks}

One hundred and seventy eight ticks (males $n=73$; females $n=95$; nymphs $n=10$ ) were collected from a total of 52 dogs. The majority (175/178) of ticks (98\%; $95 \%$ CI 95, 100) were identified as Rhipicephalus sanguineus, and three $(2 \%$; $95 \%$ CI 0,5$)$ were Amblyomma variegatum (Figure 1). These A. variegatum ticks ( 1 male, $1 \mathrm{fe}-$ male, 1 nymph) were found on one dog only, together with a single male Rhipicephalus sanguineus.

\section{Serology and microscopy test results}

Antibodies to Ehrlichia spp. and Anaplasma spp. were detected in $26 / 78$ (33\%; $95 \%$ CI 23,45$)$, and $12 / 78$ (15\%; $95 \%$ CI 8,25 ) dogs, respectively, and antigenaemia indicative of Dirofilaria immitis infection was detected in 14/78 dogs $(18 \% ; 95 \%$ CI 10, 28). None of the dogs tested positive for Borrelia burgdorferi, yet four (5\%; 95\% CI 1, 13) had co-infections with Ehrlichia and Anaplasma (Table 1). Unfortunately comprehensive blood smear assessment was not possible due to significant artefact which precluded evaluation of the red blood cells and platelets in all the smears made. This was thought retrospectively to be associated with an error in the fixation process. However, intracytoplasmic gamonts, consistent with Hepatozoon 


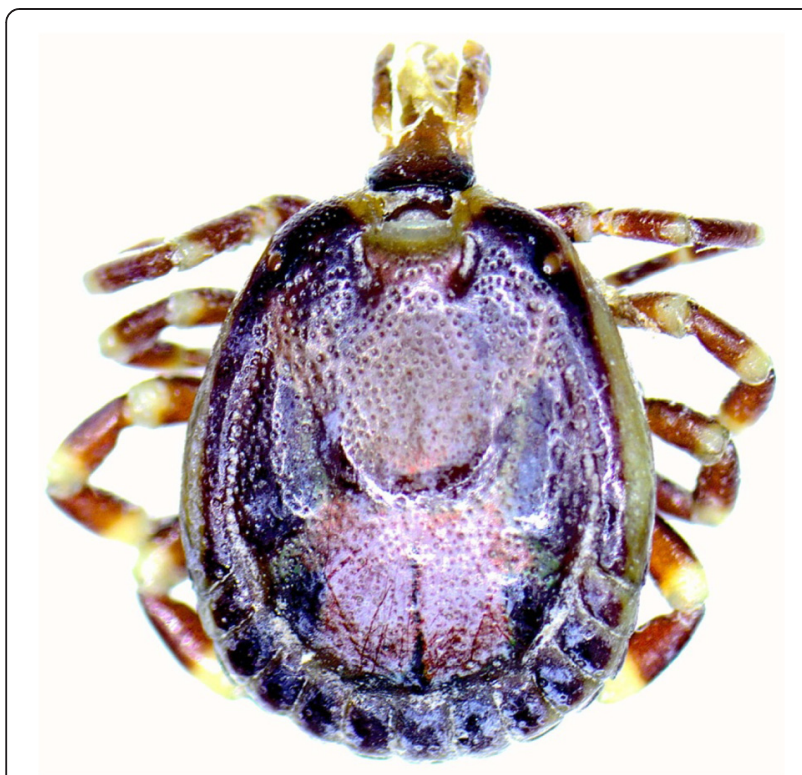

Figure 1 Male Amblyomma variegatum tick.

canis, were observed in neutrophils in the blood films of nine $(12 \%$; $95 \%$ CI 5,21$)$ of the dogs, including two dogs that were negative to all other pathogens (Figure 2). Of the 14 dogs that were positive to $D$. immitis antigen on serology, seven $(50 \%$; $95 \%$ CI 23,77$)$ had visible microfilariae on examination of the blood films. One dog had microfilariae visible on cytological examination of the blood smears, but was negative for $D$. immitis antigen.

\section{Statistical data}

Result from the ANOVA showed no significant difference in PCV between infection groups, and no significant difference in PCV in Ehrlichia spp. positive and negative groups $(\mathrm{p}=0.29)$, Anaplasma spp. positive and negative groups $(\mathrm{p}=0.43)$, and $D$. immitis positive and negative groups $(\mathrm{p}=0.40)$. However, animals which were positive for $H$. canis had significantly lower PCV values than those animals that did not harbour the pathogen $(\mathrm{p}=0.03)$ (Table 2). Tick burdens had no significant effect on PCV values $(\mathrm{p}=0.16)$.

Heavier tick burdens were significantly associated with higher numbers of pathogens diagnosed (co-infections were significantly associated with greater tick burdens) $(\mathrm{p}<0.05)$. Greater tick burdens were also significantly associated with the presence of $E$. canis and $H$. canis (Table 3). Interestingly lower tick burdens were significantly associated with the presence of $D$. immitis. Tick burdens were not associated with positive serology for Anaplasma spp. and gender did not show any significant relationship with any of the other variables.

\section{Discussion}

The dogs that were tested during this study were freeroaming strays collected throughout the island of Mauritius and kept at the MSAW pound in Port-Louis. Since it took several days to collect all the samples, new batches of dogs were continuously arriving to be assessed. In this regard therefore, the results likely provide a representative snapshot of several canine vectorborne diseases amongst the stray population throughout this southern Indian Ocean island. However, it should be noted that this stray population was unlikely to be receiving ectoparasiticide prophylaxis and may therefore not be representative of the entire canine population on the island.

Not unexpectedly, given the environmental conditions and the hosts sampled, the majority of the ticks (98\%) were $R$. sanguineus, the brown dog tick. Rhipicephalus sanguineus is the most widespread tick in the world and has been previously documented as being the most common tick found on dogs in Mauritius $[1,7,8]$. Rhipicephalus sanguineus is the main vector for $E$. canis, the cause of canine monocytic ehrlichiosis (CME), and is also responsible for the transmission of other pathogens to dogs including Babesia canis vogeli, Hepatozoon canis, and possibly Anaplasma platys [9]. In addition, in other parts of the world, $R$. sanguineus has been implicated as a vector for pathogens of human medical importance, notably Mediterranean fever (Rickettsia conorii) and other rickettsial infections (Rickettsia massiliae and Rickettsia rickettsia) $[7,10]$. The brown dog tick also serves as an intermediate host for the dog filarial parasites Cercopithifilaria bainae and Cercopithifilaria grassii, which were not tested for in this study $[10,11]$.

Interestingly, three $A$. variegatum ticks were collected from a single dog. This tick is most commonly associated with cattle in Africa but has been known to feed on other animal species including dogs and people $[1,12,13]$.

Table 1 Presence of infections in male and female dogs

\begin{tabular}{|c|c|c|c|c|c|c|c|c|c|}
\hline & $\begin{array}{l}\text { Ehrlichia } \\
\text { spp. only } \\
\text { (serology) }\end{array}$ & $\begin{array}{l}\text { Anaplasma } \\
\text { spp. only } \\
\text { (serology) }\end{array}$ & $\begin{array}{l}\text { Dirofilaria } \\
\text { immitis only } \\
\text { (serology) }\end{array}$ & $\begin{array}{l}\text { Borrelia } \\
\text { burgdorferi } \\
\text { (serology) }\end{array}$ & $\begin{array}{l}\text { Hepatozoon } \\
\text { canis only } \\
\text { (cytology) }\end{array}$ & $\begin{array}{l}\text { Ehrlichia spp. + } \\
\text { Anaplasma spp. } \\
\text { (serology) }\end{array}$ & $\begin{array}{l}\text { Ehrlichia spp. + } \\
\text { Hepatozoon canis } \\
\text { (serology + cytology) }\end{array}$ & $\begin{array}{l}\text { Hepatozoon canis + } \\
\text { Dirofilaria immitis } \\
\text { (serology + cytology) }\end{array}$ & Total \\
\hline Male & 8 & 4 & 8 & 0 & 0 & 3 & 4 & 1 & 28 \\
\hline Female & 9 & 4 & 4 & 0 & 2 & 1 & 1 & 1 & 22 \\
\hline Total & 17 & 8 & 12 & 0 & 2 & 4 & 5 & 2 & 50 \\
\hline
\end{tabular}




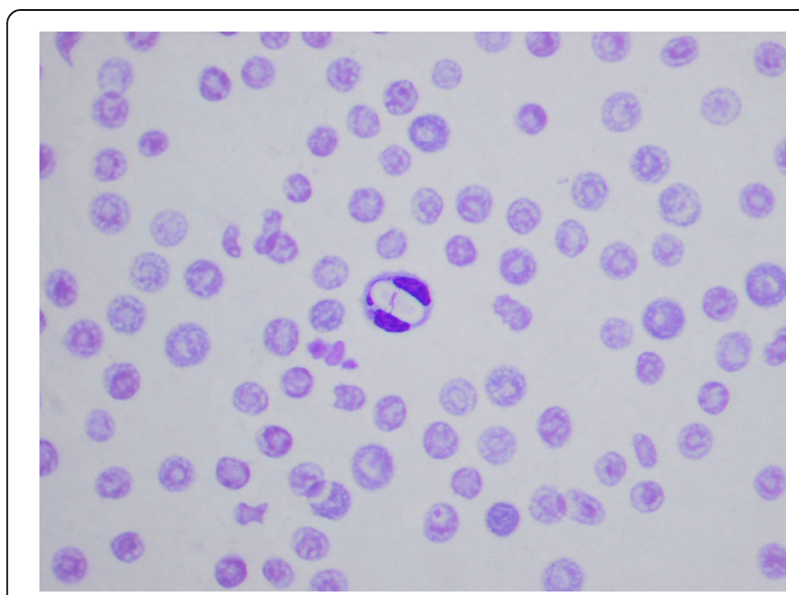

Figure 2 Hepatozoon canis gamont within a segmented neutrophil. Note the artefacts within the red blood cells.

Amblyomma variegatum is widely distributed throughout Africa and has been reported previously in Mauritius, predominantly on cattle and deer $[1,14,15]$. Our results suggest that this tick is not commonly found in the Mauritian dog population; it is possible the dog was previously in contact with cattle or deer prior to being captured and taken to the shelter, but this was not possible to verify. Amblyomma variegatum is the principal vector responsible for the spread of cowdriosis (Ehrlichia ruminantium) in tropical Africa and is also a vector for Rickettsia africae and Babesia divergens, both of which are potential human pathogens $[1,13]$. The relevance of $A$. variegatum in relation to canine vector-borne disease is unclear: that particular dog was also parasitised by $R$. sanguineus and was positive for canine ehrlichiosis.

With the widespread presence of $R$. sanguineus ticks throughout the dog population, it was not surprising to

Table 2 Relationship between the presence of pathogens and PCV values

\begin{tabular}{lllll}
\hline & & $\mathbf{n}$ & Mean PCV \pm SE & P value \\
\hline E. canis & Negative & 52 & $44.50 \pm 1.782$ & 0.29 \\
A. platys & Positive & 26 & $40.92 \pm 3.075$ & \\
& Negative & 66 & $42.77 \pm 1.770$ & 0.43 \\
H. canis & Positive & 12 & $46.25 \pm 3.050$ & \\
& Negative & 69 & $44.54 \pm 1.638$ & $0.03^{*}$ \\
D. immitis & Positive & 9 & $33.89 \pm 4.244$ & \\
& Negative & 64 & $42.69 \pm 1.734$ & 0.40 \\
No of pathogens & Positive & 14 & $46.14 \pm 1.569$ & \\
& 0 & 28 & $43.79 \pm 2.563$ & 0.39 \\
& 1 & 39 & $44.46 \pm 2.207$ & \\
& 2 & 11 & $38.00 \pm 4.507$ & \\
\hline
\end{tabular}

Abbreviations: $n$ Total number of dogs, PCV Packed Cell Volume, SE Standard Error. *- result was statistically significant. find approximately one third of the dogs tested had antibodies to Ehrlichia spp. Ehrlichia canis has not previously been documented in Mauritius, although there is clinical suspicion amongst veterinarians and anecdotal evidence of its presence in the island (Ignace, unpublished observations) [2]. Canine monocytic ehrlichiosis results in a multi-systemic disease in dogs with clinical signs that range from mild to life-threatening (e.g. terminal myelosuppressive CME) [16]. The relatively high prevalence of ehrlichial infection in the study population should alert veterinarians to the likely importance of the disease with regards to canine health in Mauritius. The diagnostic test used in this study (Snap 4Dx Plus, IDEXX laboratories, Westbrook, ME, USA) does not differentiate between E. canis and Ehrlichia ewingii, and unfortunately we were unable to investigate this further by molecular testing. Ehrlichia ewingii is believed to be transmitted by Amblyomma americanum in the southern USA and the lone star tick has never been documented in Mauritius [17]. However, there are reports of E. ewingii in Cameroon and Brazil, which are other regions not known to be enzootic for A. americanum $[18,19]$, potentially suggesting a different vector for this pathogen and we are therefore unable to confidently exclude its presence in Mauritius.

Approximately $15 \%$ of the dogs were seropositive for antibodies to Anaplasma, which could either represent Anaplasma phagocytophilum or Anaplasma platys infections (Snap 4Dx Plus, IDEXX laboratories, Westbrook, ME, USA). Anaplasma phagocytophilum is the cause of granulocytic anaplasmosis, infecting neutrophils of the canine host, and manifests clinically as non-specific signs of disease such as lameness, lethargy, pyrexia [20]. This member of the Anaplasmataceae is transmitted by Ixodes spp. ticks, which have not been previously identified on dogs in Mauritius, and their northern hemisphere distribution makes this form of anaplasmosis unlikely to occur in the island. A more plausible explanation for these results is infection by $A$. platys [21]. Anaplasma platys causes canine infectious cyclic thrombocytopenia (CICT) and may further complicate the pathogenesis of E. canis; both pathogens are generally found in similar geographical locations, both are transmitted by the same tick species, and it is common to find dogs concurrently infected with both pathogens ( $5 \%$ of the dogs in our study were infected with both A. platys and E. canis) [21].

Borrelia burgdorferi, the causative agent of Lyme disease, is transmitted by Ixodes spp. ticks. Clinical signs in dogs include lameness from inflammation of joints, lethargy and loss of appetite [22]. To the best of our knowledge autochthonous cases of Lyme disease have never been documented in Mauritius and with the presumed absence of the documented Ixodes spp. vectors, it is not believed to be present in the island. None of the dogs 
Table 3 Relationship between tick burden and presence of pathogens

\begin{tabular}{|c|c|c|c|c|c|c|}
\hline & & \multicolumn{4}{|c|}{ Tick burden } & \multirow{2}{*}{$\begin{array}{l}\text { Pearson's Chi-square } \\
\text { Asymp. Sig (2-sided) }\end{array}$} \\
\hline & & None & Low & Medium & High & \\
\hline \multirow[t]{2}{*}{ E. canis } & Negative & 22 & 18 & 10 & 2 & \multirow[t]{2}{*}{$0.00^{*}$} \\
\hline & Positive & 4 & 5 & 7 & 10 & \\
\hline \multirow[t]{2}{*}{ A. platys } & Negative & 22 & 18 & 16 & 10 & \multirow[t]{2}{*}{0.59} \\
\hline & Positive & 4 & 5 & 1 & 2 & \\
\hline \multirow[t]{2}{*}{ H. canis } & Negative & 24 & 23 & 14 & 8 & \multirow[t]{2}{*}{$0.02^{*}$} \\
\hline & Positive & 2 & 0 & 3 & 4 & \\
\hline \multirow[t]{2}{*}{ D. immitis } & Negative & 17 & 20 & 15 & 12 & \multirow[t]{2}{*}{$0.04^{*}$} \\
\hline & Positive & 9 & 3 & 2 & 0 & \\
\hline \multirow[t]{3}{*}{ No of pathogens } & 0 & 8 & 12 & 7 & 1 & \multirow[t]{3}{*}{$0.02^{*}$} \\
\hline & 1 & 17 & 9 & 7 & 6 & \\
\hline & 2 & 1 & 2 & 3 & 5 & \\
\hline
\end{tabular}

Abbreviations: Asymp. Sig Asymptotic significance.

*- result was statistically significant.

tested in this study returned a positive antibody test to the C6 antigen, a specific and highly conserved antigen expressed by members of the Borrelia burgdorferi genogroup sensu lato.

Hepatozoonosis in dogs is caused by two species; $H$. americanum and $H$. canis. To date, $H$. americanum has only been found in the United States and is transmitted by Amblyomma maculatum in that country. $H$. canis causes a much milder disease (anaemia, lethargy and often subclinical) and is transmitted by $R$. sanguineus throughout the world [23,24]. Despite causing mild disease, $H$. canis was found to be associated with lower PCV values in our dog population $(p=0.03)$. This may be explained by the fact that only two dogs had single infections with $H$. canis, and that lower PCV values may actually be due to co-infections with other pathogens.

Hepatozoonosis is more difficult to diagnose as serological testing is not readily available for the causative pathogen, and either blood smears or PCR are required instead for diagnosis. The white cells were able to be visualised clearly by microscopy and $H$. canis gamonts were seen within the neutrophils of nine dogs. This is the first record of canine Hepatozoon infection in Mauritius.

Dirofilaria immitis is the cause of heartworm disease and is transmitted by mosquitoes. It has a worldwide distribution. Clinical signs include coughing, lethargy and exercise intolerance but some dogs have subclinical disease. The test used in this study detects $D$. immitis antigen from mature female worms only, therefore, a positive result indicates infection with at least one mature female heartworm ( $>6$ months old) [21]. Interestingly 7 out of the 14 antigen positive dogs (50\%; 95\% CI 23,77 ) were amicrofilaraemic on examination of blood smears, indicating the presence of occult infections in these dogs [25]. High percentages of occult infections are not uncommon in endemic areas and have previously been reported in central Portugal [26,27]; such infections have obvious diagnostic implications as clinicians must be careful when ruling out heartworm disease on the basis of microscopic work alone. Regardless, visualising microfilariae in blood smears is an insensitive way of quantifying the disease burden and should not be used as a singular method of diagnosis.

Curiously, one of the dogs was negative for the D. immitis antigen, but had visible microfilariae on microscopic examination. This may be explained by a false negative serological result (sensitivity of 99.0\%- SNAP 4Dx Plus, IDEXX laboratories, Westbrook, ME, USA), or the dog was infected with a different filarial organism. Other filarial organisms that could present with microfilariae include, and are not limited to, Dirofilaria repens, Acanthocheilonema reconditum, Acanthocheilonema dracunculoides, Brugia malayi, Brugia pahangi [28]. Results from Chisquare testing also revealed a statistically significant relationship between lower tick burdens and infection with $D$. immitis infection. This could be coincidental or may reflect the fact that the dogs came from various parts of the island where mosquitoes with heartworm may be more prevalent in areas where ticks are less numerous.

A previous study carried out by Gaunt et al. showed that dogs co-infected with both $E$. canis and $A$. platys had more severe anaemia and thrombocytopenia, and a more persistent $A$. platys infection with a stronger immune response [29]. In our study, the number of pathogens the dogs were infected with did not have any statistically significant effect on PCV values, indicating that co-infected dogs did not show greater levels of anaemia. However, it must be acknowledged that PCV is not necessarily a reliable indicator of the degree of pathology for the vector-borne diseases we tested for, and 
that thrombocyte count may be more useful, but this would have required more sophisticated equipment. Furthermore, the unavailability of molecular analysis of the blood samples, such as by PCR, is acknowledged as a limitation of this diagnostic study, and this deficit should be addressed in any future studies of CVBD on Mauritius.

The relationship between tick burdens and infection rates was also assessed. Studies have shown that high tick burdens do not correlate with mortality or infection from tick-borne disease because not all ticks harbour pathogens [30,31]. This, however, was not the case with our study: our results showed that higher tick burdens were associated with $E$. canis and $H$. canis infections, as well as higher co-infection rates. This appears to be logical, as the more ticks a dog is infected with, the higher the chances of it contracting vector-borne pathogens.

\section{Conclusions}

This is the first study to investigate the presence of canine vector-borne diseases in Mauritius. Our preliminary data confirm the presence of canine ehrlichiosis, anaplasmosis, hepatozoonosis and heartworm disease within the island, and show that dogs are at a high risk of harbouring these pathogens. Additional research based on molecular methods is required for evaluating the presence of Babesia spp., especially B. c. vogeli as its vector $R$. sanguineus is known to be present on the island. A more thorough link between haematological parameters and clinical presentation would also strengthen our knowledge about the vector-borne diseases on the island. This study also confirms the presence of $R$. sanguineus and A. variegatum in the dog population, with $R$. sanguineus being the most common tick parasitising dogs. High tick burdens were associated with greater infections from tick-borne diseases.

\section{Competing interests}

The authors declare they have no competing interests.

\section{Authors' contributions}

GKCL participated in the design of the study, organized the field work, collected the data, analysed the results and wrote the manuscript. JAEI assisted with the field work and data collection. IDR was involved in interpreting the results and providing statistical advice. PJI designed the study and supervised all stages of the work. All authors have read and approved the final version of the manuscript.

\section{Acknowledgements \\ The authors wish to thank the President and Committee of the Mauritius Society for Animal Welfare (MSAW) for permitting this study and facilitating access to the dogs at the MSAW shelter. We are grateful to Ms Sharon Curtis and Idexx Australia for kindly supplying the Snap 4Dx plus kits used in this study. We also acknowledge assistance in tick identification provided by Professor G Miro and Ms T Greay, and would also like to thank Mr SKC Lee for his help in the collection of samples.}

\section{Author details}

${ }^{1}$ Vector and Water-Borne Pathogen Research Group, School of Veterinary and Life Sciences, Murdoch University, Murdoch, WA 6150, Australia. ${ }^{2}$ Sir Seewoosagur Ramgoolam Animal Hospital, Mauritius Society for Animal Welfare, Rose Hill, Mauritius.
Received: 23 November 2014 Accepted: 10 March 2015

Published online: 23 March 2015

\section{References}

1. Barré N, Morel PC. Tiques (Acariens, Ixodoidea) des Mascareignes (Océan Indien) et maladies transmises. Rev Elev Med Vet Pays Trop. 1983;36(4):371-8.

2. Taylor MA, Jackson V, Zimmer I, Huntley S, Tomlinson A, Grant A: Qualitative Veterinary Risk Assessment: Introduction of Exotic Diseases (other than Rabies) in the UK. Appendix 5: Disease Distribution Tables [http://archive. defra.gov.uk/foodfarm/farmanimal/diseases/atoz/rabies/documents/ appendix5.pdf]

3. Rojas A, Rojas D, Montenegro V, Gutierrez R, Yasur-Landau D, Baneth G. Vector-borne pathogens in dogs from Costa Rica: first molecular description of Babesia vogeli and Hepatozoon canis infections with a high prevalence of monocytic ehrlichiosis and the manifestations of co-infection. Vet Parasitol. 2014;199:121-8.

4. Walker AR, Bouattour A, Camicas JL, Estrada-Pena A, Horak IG, Latif AA, et al. Ticks of domestic animals in Africa: a guide to identification of species. Edinburgh: Bioscience Reports; 2013.

5. Walker JB, Keirans JE, Horak IG. The genus rhipicephalus (acari, ixodidae): a guide to the brown ticks of the world. Cambridge: Cambridge University Press; 2000.

6. Allison RW, Meinkoth $\mathrm{JH}$. Hematology without the numbers: in-clinic blood film evaluation. Vet Clin Small Anim. 2007;37:245-66.

7. Fourie JJ, Stanneck D, Luus HG, Beugnet F, Wijnveld M, Jongejan F. Transmission of Ehrlichia canis by Rhipicephalus sanguineus ticks feeding on dogs and on artificial membranes. Vet Parasitol. 2013;197:595-603.

8. Dantas- Torres F. The brown dog tick, Rhipicephalus sanguineus (Latreille 1806) (Acari: Ixodidae): from taxonomy to control. Vet Parasitol. 2008;25:173-85.

9. Waner T, Harrus S. Canine monocytic ehrlichiosis- from pathology to clinical manifestations. Isr J Vet Med. 2013;68:12-8.

10. Latrofa MS, Dantas-Torres F, Giannelli A, Otranto D. Molecular detection of tick-borne pathogens in Rhipicephalus sanguineus group ticks. Ticks Tick Borne Dis. 2014;5:943-6.

11. Brianti E, Otranto D, Dantas-Torres F, Weigl S, Latrofa MS, Gaglio G, et al. Rhipicephalus sanguineus (Ixodida, Ixodidae) as intermediate host of a canine neglected filarial species with dermal microfilariae. Vet Parasitol. 2012;183:330-7.

12. Barré N, Camus E, Borel G, Aprelon R. Sites de fixation de la tique Amblyomma variegatum sur ses hôtes en Guadeloupe (Antilles françaises). Rev Elev Med Vet Pays Trop. 1991;44(4):453-8.

13. Ogo NI, Fernandez de Mera IG, Galindo RC, Okubanjo OO, Inuwa HM, Agbede RIS, et al. Molecular identification of tick-borne pathogens in Nigerian ticks. Vet Parasitol. 2012;187:572-7.

14. Walker JB, Olwage A. The tick vectors of Cowdria ruminantium (Ixodida, Ixodidae, genus Amblyomma) and their distribution. Onderstepoort J Vet. 1987;54(3):353-79.

15. Stachurski F, Tortosa P, Rahajarison P, Jacquet S, Yssouf A, Huber K. New data regarding distribution of cattle ticks in the south-western Indian Ocean islands. Vet Res. 2013;44(1):79-87.

16. Mylonakis ME, Xenoulis PG, Theodorou K, Siarkou VI, Steiner JM, Harrus S, et al. Serum canine pancreatic lipase immunoreactivity in experimentally induced and naturally occurring canine monocytic ehrlichiosis (Ehrlichia canis). Vet Microbiol. 2014;169:198-202.

17. Wright CL, Gaff HD, Hynes WL. Prevalence of Ehrlichia chaffeensis and Ehrlichia ewingii in Amblyomma americanum and Dermacentor variabilis collected from southeastern Virginia, 2011-2012. Ticks Tick Borne Dis. 2014;5(6):978-82.

18. Ndip LM, Ndip RN, Esemu SN, Dickmu VL, Fokam EB, Walker DH, et al. Ehrlichial infection in Cameroonian canines by Ehrlichia canis and Ehrlichia ewingii. Vet Microbiol. 2005;111(1-2):59-66.

19. Oliveira LS, Oliveira KA, Mourao LC, Pescatore AM, Almeida MR, Conceicao $L G$, et al. First report of Ehrlichia ewingii detected by molecular investigation in dogs from Brazil. Clin Microbiol Infect. 2009;15:55-6.

20. Little S. Ehrlichiosis and anaplasmosis in dogs and cats. Vet Clin North Am Small Anim Pract. 2010;40:1121-40.

21. Stillman BA, Monn M, Liu J, Thatcher B, Foster P, Andrews B, et al. Performance of a commercially available in-clinic ELISA for detection of antibodies against Anaplasma phagocytophilum, Anaplasma platys, Borrelia 
burgdorferi, Ehrlichia canis, and Ehrlichia ewingii and Dirofilaria immitis antigen in dogs. J Am Vet Med Assoc. 2014;245(1):80-6.

22. Krupka I, Straubinger RK. Lyme borreliosis in dogs and cats: background, diagnosis, treatment and prevention of infections with Borrelia burgdorferi sensu stricto. Vet Clin North Am Small Anim Pract. 2010;40:1103-19.

23. Irwin PJ, Jefferies R. Arthropod-transmitted diseases of companion animals in Southeast Asia. Trends Parasitol. 2004;20(1):27-34.

24. Yabsley MJ, McKibben J, Macpherson CN, Cattan PF, Cherry NA, Hegarty BC, et al. Prevalence of Ehrlichia canis, Anaplasma platys, Babesia canis vogeli, Hepatozoon canis, Bartonella vinsonii berkhoffii, and Rickettsia spp. in dogs from Grenada. Vet Parasitol. 2008;151:279-85.

25. Rawlings CA, Dawe DL, McCall JW, Keith JC, Prestwood AK. Four types of occult Dirofilaria immitis infection in dogs. J Am Vet Med Assoc. 1982;180(11):1323-6.

26. Vieira AL, Vieira MJ, Oliveira JM, Simoes AR, Diez-Banos P, Gestal J. Prevalence of canine heartworm (Dirofilaria immitis) diseases in dogs of central Portugal. Parasite. 2014;21(5):1-7.

27. McCall J, Genchi C, Kramer L, Guerrero J, Dzimianski M, Supakorndej P, et al. Heartworm and Wolbachia: therapeutic implication. Vet Parasitol. 2008;158:204-14

28. Megat Abd Rani PA, Irwin PJ, Gatne M, Coleman GT, Mclnnes LM, Traub RJ. A survey of canine filarial diseases of veterinary and public health significance in India. Parasit Vectors. 2010;3:30.

29. Gaunt S, Beall M, Stillman B, Lorentzen L, Diniz PPVP, Chadrashekar R, et al. Experimental infection and co-infection of dogs with Anaplasma platys and Ehrlichia canis: Hematologic, serologic and molecular findings. Parasit Vectors. 2010;3:33.

30. Laisser ELK, Kipanyula MJ, Msalya G, Mdegela RH, Karimuribo ED, Mwilawa AJ, Mwega ED, Kusiluka L, Chenyambuga SW. Tick burden and prevalence of Theileria parva infection in Tarime zebu cattle in the lake zone of Tanzania. Trop Anim Health Prod, in press.

31. Hersh MH, LaDeau SL, Previtali MA, Ostfeld RS. When is a parasite not a parasite? Effects of larval tick burdens on white-footed mouse survival. Ecology. 2014;95(5):1360-9.

\section{Submit your next manuscript to BioMed Central and take full advantage of:}

- Convenient online submission

- Thorough peer review

- No space constraints or color figure charges

- Immediate publication on acceptance

- Inclusion in PubMed, CAS, Scopus and Google Scholar

- Research which is freely available for redistribution 